\title{
Carotid siphon geometry and variants of the circle of Willis in the origin of carotid aneurysms
}

\author{
Geometria do sifão carotídeo e variantes do polígono de Willis na origem de \\ aneurismas da carótida
}

Ângelo Raimundo Silva Neto', Ródio Luis Brandão Câmara², Marcelo Moraes Valença

\begin{abstract}
This study evaluated anatomical variants in the carotid siphon and of the circle of Willis in patients with aneurysms. We performed a retrospective analysis of cerebral angiographies. The Control Group was composed of patients without aneurysms. Posterior communicating artery (PcomA) aneurysms were more common in women ( $p<0.05)$, and the anterior communicating artery (AcomA) aneurysms in men ( $p<0.1)$. The incidence of fetal-type PcomA was higher in cases with co-occurring PcomA aneurysm (24 versus 8\%, p<0.05). Patients with AcomA aneurysm had higher incidence of A1 hypoplasia ( $p<0.0001, \mathrm{OR}=32.13,95 \% \mathrm{Cl} 12.95-79.71)$ and lower frequency of fetal-type PcomA compared to their control counterparts $(p=0.0125)$. The angle of carotid siphon was narrower in patients with PcomA aneurysm (27.3 \pm 19.1 versus $34.8 \pm 22.6, p=0.028)$. In conclusion, a narrower carotid siphon or the presence of fetal-type PcomA or A1 hypoplasia may cause hemodynamic stress, thereby promoting the formation of aneurysms in susceptible individuals.
\end{abstract}

Key words: intracranial aneurysm, carotid siphon, fetal communicating artery, A1 hypoplasia, carotid artery.

\section{RESUMO}

O presente estudo avaliou as variantes anatômicas do sifão carotídeo e da parte posterior do polígono de Willis em pacientes com aneurismas. Foi realizada uma análise retrospectiva de angiografias cerebrais. O Grupo Controle foi composto por pacientes sem aneurismas. Aneurismas da artéria comunicante posterior (ACP) foram mais frequentes em mulheres $(p<0,05)$, e aqueles da anterior (ACA) em homens $(p<0,1)$. A incidência do tipo fetal da ACP foi maior nos casos com co-ocorrência de aneurisma da ACP ( 24 versus 8\%, $p<0,05)$. Pacientes com aneurisma da ACA tiveram maior incidência de hipoplasia A1 ( $p<0,0001,0 R=32,13$, IC95\% 12,95-79,71) e menor frequência do da ACP fetal comparados com os controles ( $p=0,0125)$. O ângulo do sifão carotídeo era mais estreito em pacientes com aneurismas da ACP (27,3 $\pm 19,1$ versus 34,8 $\pm 22,6, p=0,028$ ). Em conclusão, um sifão carotídeo estreito e a presença de ACP fetal ou hipoplasia A1 podem causar estresse hemodinâmico, promovendo a formação de aneurismas em indivíduos suscetíveis.

Palavras-Chave: aneurisma cerebral, sifão carotídeo, artéria comunicante fetal, hipoplasia A1, artéria carótida.

Brain aneurysm is one of the most challenging affections within the brain ${ }^{1-3}$. Its rupture is the most common cause of spontaneous subarachnoid hemorrhage $e^{4}$, accounting for a large number of deaths and disabilities $^{4,5}$. The origin of aneurysms remains uncertain, but it is known to have multifactorial causes. Hemodynamic stress, for instance, seems to be a major factor in the formation of aneurysms ${ }^{6-8}$.

Over the last two decades, the detection of unruptured aneurysms has increased due to advances in neuroimaging ${ }^{3,9}$. However, the natural history of unruptured aneurysms is still scarcely understood ${ }^{3,10}$. Multicenter studies, including the International Study of Unruptured Intracranial Aneurysms
(ISUIA), have attempted to demonstrate risk factors and guidance for patients with such condition ${ }^{11}$.

The internal carotid artery (ICA) at its junction with the posterior communicating artery (PcomA) is one of the most frequent sites for the appearance of saccular aneurysms ${ }^{1,12-14}$. These aneurysms are prevalent in women and usually occur after their fourth or fifth decades of life ${ }^{6}$. A factor that might explain this difference in frequency is a possible anatomic variation in the circle of Willis between genders. This issue has been recently discussed in the literature ${ }^{6,12}$.

PcomA aneurysms have a special relationship with a part of the ICA called carotid siphon. We have found a considerable range of shapes and angle sizes in the carotid

${ }^{1}$ Hospital Universitário Onofre Lopes, Natal RN, Brazil;

2Department of Neurosurgery, Universidade Federal do Rio Grande do Norte (UFRN), Natal RN, Brazil;

${ }^{3}$ Neurosurgery Unit, Department of Neuropsychiatry, Universidade Federal de Pernambuco (UFPE), Recife PE, Brazil.

Correspondence: Ângelo Raimundo Silva Neto; Avenida Professor Moraes Rego s/n; 50670-901 Recife PE - Brasil; E-mail: angelo@neuronrn.com.br

Conflict of interest: There is no conflict of interest to declare.

Received 12 December 2011; Received in final form 10 July 2012; Accepted 17 July 2012 
siphon of patients with and without aneurysms, which may affect hemodynamic stress on the ICA-PcomA junction, thereby promoting aneurysm formation in that segment ${ }^{15}$. However, only a few studies mention the carotid siphon as an anatomical variable involved in the incidence of intracranial aneurysms ${ }^{16}$.

In the present study, we performed a retrospective analysis of cerebral angiographies in patients with anterior communicating artery (AcomA), middle cerebral artery (MCA), or PcomA aneurysms. We aimed at detecting anatomical variations in the carotid siphon and in the circle of Willis, as well as their relationship with the incidence of aneurysms in the carotid territory. For the sake of comparison, we have also studied the angiographic findings of a Control Group including patients without aneurysms.

\section{METHODS}

From December 2001 to December 2007, 542 patients were submitted to cerebral angiography at the image sector of Onofre Lopes University Hospital in Natal, Brazil, a center specialized in endovascular neurosurgery. We accessed the results of 512 of these examinations (no reports were recorded from 30), and after approval was obtained from the institutional ethics committee (Research Ethics Committee - Universidade Federal do Rio Grande do Norte), 169 patients (48.8 \pm 19.2 years-old, 109 women) whose angiographies revealed cerebral aneurysms were selected. The Control Group consisted of 256 individuals that underwent cerebral angiography for multiple reasons, but no aneurysm was found during angiographic evaluation.

Patients were divided into groups based on aneurysm site: 59 PcomA, 59 AcomA, and $40 \mathrm{MCA}$ aneurysms. Each angiography was identified and information on age, gender, side of the aneurysm, carotid siphon angle, and type of anatomic abnormality of the circle of Willis was recorded. Sixty-three control patients were randomly selected for a study of the carotid siphon angle.

The examinations were performed with a Philips Integris V5000 (Philips Medical Systems; Best, The Netherlands). The research was focused on films of the carotid artery in the lateral view of both sides and on anteroposterior sequences of the vertebrobasilar system. All patients included in the study had at least one complete investigation of the carotid system on one of the sides, in addition to the vertebrobasilar system.

\section{Studied variables}

Differences between carotid siphon angles were assessed using degree measures. Relationships between them and other categorical variables, such as gender, age, side of the aneurysm, and posterior circulation type of the circle of Willis ( fetal and adult) were also investigated.

\section{Calculation of the carotid siphon angle}

Initially, a pattern for the lateral angiographic examination of the intracranial carotid artery was established, in which all parts of the carotid siphon and the PcomA could be included. This limited the number of control angiograms for this purpose (63 patients). Based on the anatomical division proposed by Rhoton ${ }^{1}$, the ICA was divided into the following segments: C3 (intracavernous) and C4 (supraclinoid).

Using the Image J Version 1.42p (NIH Image) program, we drew two straight lines starting at the midpoints of the arterial diameters of the segments under question. The angle was measured at the point where these straight lines met (Fig 1).

\section{Type of internal carotid artery-posterior} communicating artery circulation

Based on the literature, variations in the posterior circulation of the circle of Willis were classified into two types ${ }^{17}$. We considered the relation of the PcomA to the posterior cerebral artery (PCA) on the antero posterior (AP) view of the vertebral artery. Thus, type A, also known as the adult type, has a longer PCA diameter in relation to the PcomA, whereas the fetal type does not show the arterial vessels related to the PcomA on the AP view of the vertebral artery. Also, the carotid system contributed much more to circulation to the occipital lobes.

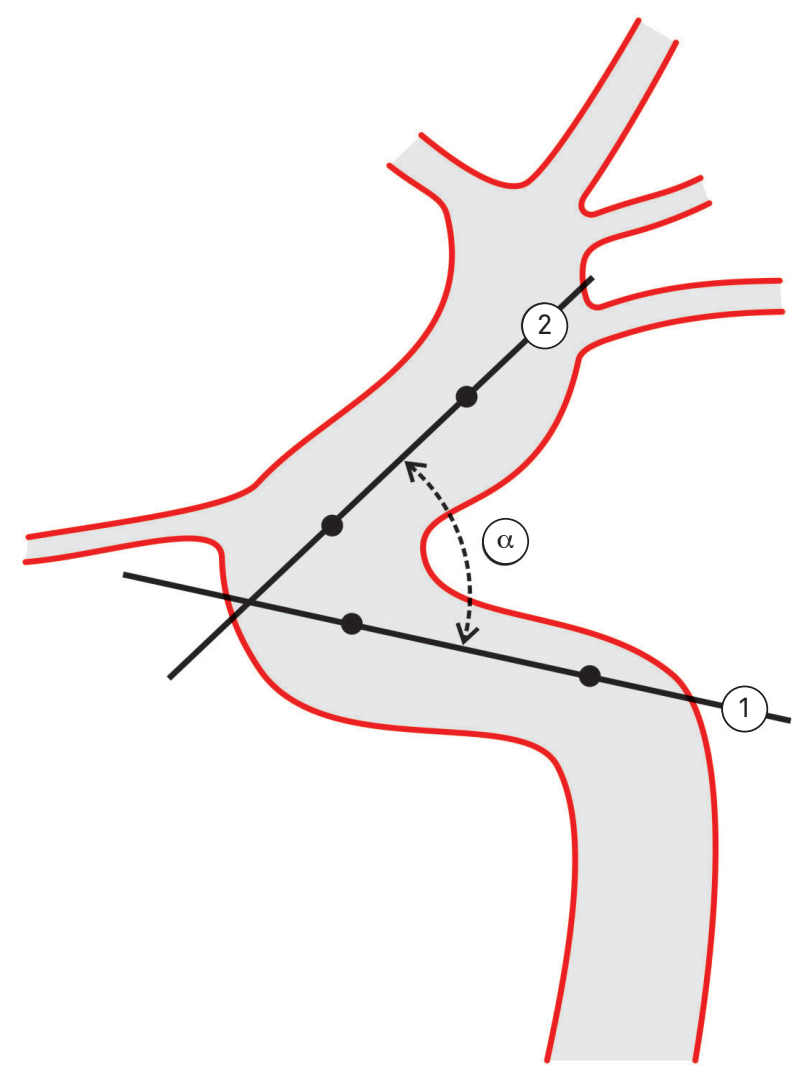

Fig 1. Carotid siphon angle $(\alpha)$ formed by the intersection of two lines traced from intracavernous (1) and supraclinoid (2) points through the artery. 


\section{Statistical analysis}

Patients were descriptively distributed by gender, presence of aneurysm, side of aneurysm, and type of ICA-PcomA circulation. In the case of categorical variables, Pearson's $\chi^{2}$ was applied.

To assess the statistical differences between the carotid siphon angles, Student's t-test for dependent samples was used to compare angles on the right and left sides, and the same for independent samples was used to compare differences between patients with aneurysms and controls.

Before performing the parametric analysis of the quantitative data, we verified whether the residues behaved according to normal distribution with $\mathrm{p}<0.05$ using the KolmogorovSmirnov test, as well as a normal Q-Q plot graph. Based on these results, we analyzed the abovementioned tests. The significance level established for all tests was $5 \%(p<0.05)$.

\section{RESULTS}

A gender comparison between each of the three groups with cerebral aneurysms and the Control Group is shown in Table 1. PcomA aneurysms were more common in females $(\mathrm{p}<0.05)$, and AcomA ones in males $(\mathrm{p}<0.1)$.

The frequency of fetal-type PcomA was significantly higher in PcomA aneurysms (24 versus 8\%, $\mathrm{p}<0.05$; $\mathrm{OR}=2.102$, 95\%CI 1.041-4.245), as shown in Table 2. On the other hand, we found higher incidence of Al hypoplasia in association with AcomA aneurysms ( $<<0.0001, \mathrm{OR}=32.13,95 \% \mathrm{CI}$ 12.95-79.71) and a low frequency of fetal type of PcomA in this group compared to the controls $(p=0.0125)$. When AcomA and MCA aneurysms $(2 / 99,2.0 \%)$ were analyzed in a single group, the chance of fetal PcomA occurrence in an arterial angiography was six-times lower than in the Control Group ( $\mathrm{p}=0.0021$, $\mathrm{OR}=0.1393$; CI95\% 0.03277-0.5925). Concerning A1 hypoplasia, no statistical differences were found between groups with aneurysm (excluding AcomA) and the Control Group:
PcomA and MCA 1/99 - 1.0\% versus Control (7/256-2.7\%), $\mathrm{p}=0.3263, \mathrm{OR}=0.3630,95 \%$ CI $0.04406-2.990$.

Table 3 shows a comparison between patients with aneurysms and the controls in terms of carotid siphon angle and gender. The mean angle value found in the groups with aneurysms was statistically lower $(27.3 \pm 19.1$ versus $34.8 \pm 22.6)$ than in the Control Group ( $\mathrm{p}=0.028)$. When the male group was analyzed, no statistical differences were seen $(p=0.367)$.

\section{DISCUSSION}

The prevalence of certain types of aneurysm is known to be gender-dependent, whereas patient's age on rupture is associated with the aneurysm site ${ }^{6}$. Recent attempts to explain these differences have led some authors to consider anatomical aspects of intracranial arterial vasculature related to the development of aneurysms $s^{5-7,16}$.

With regards to aneurysm location by gender, MCA and AcomA aneurysms are more commonly found in men, whereas aneurysms of the basilar vertebral system and the ICA are more prevalent in women ${ }^{5,18}$. This difference was not clarified in previous studies, raising an issue about the role of anatomical differences between genders in the circle of Willis, which may cause hemodynamic stress that results in the formation of aneurysms ${ }^{6}$.

The increasing appearance of new technologies for radiological investigation has greatly enhanced the detection of cerebral aneurysms, especially the unruptured ones. This prompted the study of the natural history of these lesions over the last two decades.

The main event in the natural history of an aneurysm is undoubtedly its rupture ${ }^{2}$. Subarachnoid hemorrhage is still responsible for a high rate of lethality and morbidity. A recent international study on unruptured aneurysms (ISUIA) ${ }^{9-12}$, in its prospective phase, demonstrated that according to the
Table 1. Aneurysm location in men and women.

\begin{tabular}{lccc}
\multirow{2}{*}{ Gender } & \multicolumn{3}{c}{ Location } \\
\cline { 2 - 4 } & PcomA & AcomA & MCA \\
\hline Men & $11 / 49(22 \%)$ & $23 / 49(47 \%)$ & $15 / 49(30 \%)$ \\
Women & $48 / 109(44 \%)^{a}$ & $36 / 109(33 \%)$ & $25 / 109(23 \%)$ \\
\hline
\end{tabular}

PcomA: posterior communicating artery; AcomA: anterior communicating artery; MCA: middle cerebral artery. Superscript letters indicate differences between the genders ( ${ }^{a} \mathrm{p}=0.0095, \chi^{2}$ test).
Table 3. Gender-dependent siphon angle in patients with and without posterior communicating artery aneurysms.

\begin{tabular}{lccc}
\multirow{2}{*}{ Gender } & \multicolumn{2}{c}{ Angle $\left({ }^{\circ}\right)$} & - \\
\cline { 2 - 3 } & Control Group & Aneurysms & \\
\hline Total & $34.8 \pm 22.6(n=63)$ & $27.3 \pm 19.1(n=59)$ & 0.028 \\
Male & $34.3 \pm 22.6(n=32)$ & $29.0 \pm 7.9(n=12)$ & 0.367 \\
Female & $38.4 \pm 23.9(n=31)$ & $26.8 \pm 19.6(n=47)$ & 0.012 \\
\hline \multicolumn{2}{l}{ Data are shown as mean \pm standard deviation; *Student’s t-test. }
\end{tabular}

Table 2. Anatomic variants (fetal-type posterior communicating artery and A1 hypoplasia) in the groups.

\begin{tabular}{|c|c|c|c|c|}
\hline \multirow{2}{*}{ Group } & \multirow{2}{*}{ Aneurysm location } & \multirow{2}{*}{$\mathrm{n}$} & \multicolumn{2}{|c|}{ Anatomic variant } \\
\hline & & & Fetal PcomA & A1 hypoplasia \\
\hline & PcomA & 59 & $14 / 59(23.7 \%)^{a}$ & $1 / 59(1.5 \%)$ \\
\hline \multirow[t]{2}{*}{ Aneurysms } & AcomA & 59 & $1 / 59(1.5 \%)^{b}$ & $28 / 59(47.5 \%)^{d}$ \\
\hline & MCA & 40 & $1 / 40(2.5 \%)^{c}$ & $0 / 40(0.0 \%)$ \\
\hline Control Group & & 256 & $33 / 256(12.0 \%)$ & $7 / 256(2.7 \%)$ \\
\hline
\end{tabular}

PcomA: posterior communicating artery; AcomA: anterior communicating artery; MCA: middle cerebral artery. Superscript letters indicate differences between the groups with aneurysms and the Control Group ( ${ }^{a} p=0.0352,{ }^{b} p=0.0125,{ }^{c} p=0.055,{ }^{d} p<0.0001 ; \chi^{2}$ test). 

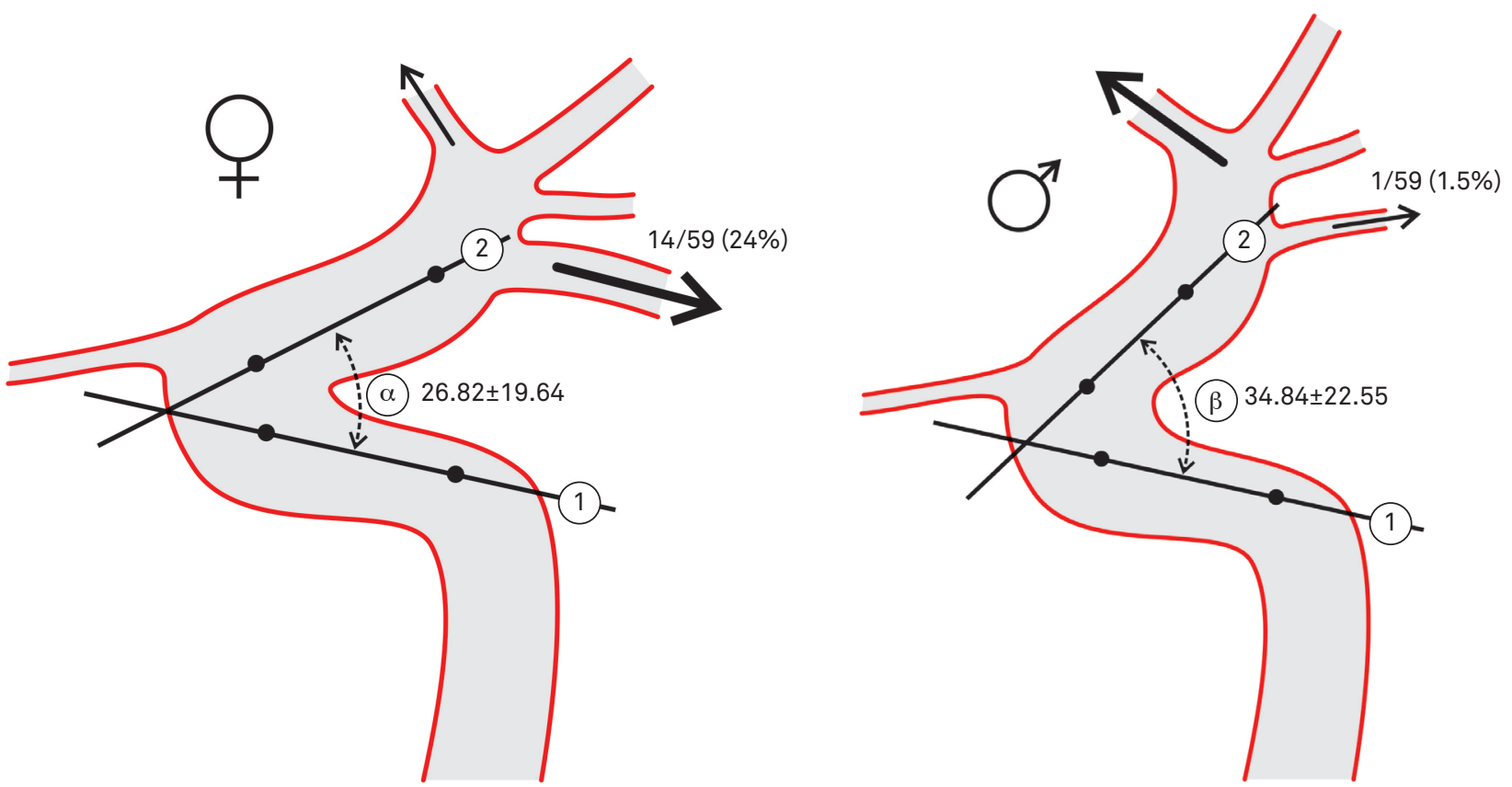

Fig 2. Aneurysms of the posterior and anterior communicating arteries in men and women.

natural history of an aneurysm, size is one of the main determinants for its rupture.

Although criticized by many authors for its patient selection mode ${ }^{19}$, the ISUIA demonstrated that aneurysms of the PcomA, posterior cerebral artery region, and basilar artery, all larger than $12 \mathrm{~mm}$ when diagnosed, had different bleeding rates over five years. These aneurysms had $50 \%$ bleeding occurrences, whereas those in other locations had a much lower rate of 1 to $2 \%$ per year (i.e. carotid territory) ${ }^{12}$.

Aneurysm location is therefore an important factor in guiding therapeutic decisions. The different behavior of PcomA aneurysms, not only due to gender-related prevalence, but also because of the high bleeding risk they pose when they become large, encouraged the authors of this article to study a variable that has not yet been examined extensively in the literature: the geometrical shape of the carotid siphon.

In the present study, we found a marked difference in PcomA aneurysms between the genders. There was low incidence of fetal-type PcomA in patients with AcomA aneurysms ( $\mathrm{p}=0.0125$ ), compared to the Control Group. The fetal type PcomA is associated with high flow rates in the carotid system, and low ones in the basilar artery. This evidence was studied by Hendrikse et al. ${ }^{20}$. This flow diversion to the posterior cerebral artery could protect these patients from the formation of aneurysms in the distal part of the carotid artery system, such as the anterior communicating complex.

The high number of aneurysms that we found in arteries with narrow siphon confirmed the initial suspicion and the leading hypothesis for this work. The detection of statistical significance only in data from the left side $(p=0.030)$ was surprising and inexplicable. One possibility for it is the reduced number of male patients with PcomA aneurysms $(\mathrm{n}=12)$, because a smaller angle was also observed in this population $\left(29.0 \pm 17.9^{\circ}\right.$ versus $\left.34.3 \pm 22.6^{\circ}\right)$.

Vessel curvature has been studied in other parts of the arterial system, where geometrical variations were related to a number of pathological alterations. In the case of coronary arteries, this was evidenced and associated with high atherosclerotic plaque development ${ }^{21}$.

We know that the procedure adopted to gauge carotid siphon angle may be biased and other measurement methods with better reproducibility may appear in the future. Our greatest challenge was to measure this angle in overly tortuous arteries, particularly at the beginning of the siphon, where the carotid artery is still in the cavernous segment. In this case, the best analysis would be provided by tridimensional measurements ${ }^{8}$. We must remember that the carotid siphon has other lateral curves in addition to the curvatures seen in the lateral angiography, thereby resembling a helical shape as defined by some authors ${ }^{8,16}$. We were not able to measure such curves. On some occasions, the giant PcomA aneurysms prevented the visualization of segments that were necessary for gauging. Therefore, one of our patients was excluded from the final analysis. Even considering these comments, the measurements performed in the lateral view are worth considering for they are an easy way to evaluate a probable risk factor for aneurysm development or even to predict an aneurismal rupture caused by a supposed high hemodynamic stress over an incidental small aneurysm.

The great incidence of aneurysms in the siphons with closed angles is probably a consequence of strong hemodynamic 
stress, which would make patients more prone to develop PcomA aneurysms with a high chance of rupture ${ }^{22}$.

Any unruptured aneurysm must have individualized treatment that considers, in addition to its size, the general medical conditions of the patients, age and life perspectives ${ }^{23}$. Since it is a potentially lethal lesion, useful information concerning hemodynamic variables, even assessed indirectly as analyzed here, must be considered as a whole and should be given greater importance in future studies. We found a statistical difference between men and women with respect to the PcomA aneurysm. We believe that the highest prevalence of PcomA in women may be due to at least two causes: higher frequency of fetal type PcomA and smaller angle of the carotid siphon. However, we have no idea whether the studied variable - carotid siphon angle - could be subjected to alterations across the different phases of life, thus suffering the influence of either hormonal ${ }^{24,25}$ or atherosclerotic factors. In the present study, the incidence of A1 hypoplasia was 17 times higher in patients with AcomA aneurysm compared to the controls. On the other hand, an inverse relationship was observed between AcomA aneurysms and fetal-type PcomA occurrence, likely because of the low hemodynamic stress on the anterior segment of the carotid circulation when a fetal PcomA artery was ipsilaterally present (Fig 2).

In conclusion, a narrower carotid siphon or the presence of a fetal-type PcomA may alter hemodynamic stress and consequently influence the formation of both PcomA and AcomA aneurysms in susceptible individuals.

\section{References}

1. Rhoton Jr AL. Aneurysms. Neurosurgery 2002;51(Suppl 4):S121-S158.

2. Brisman JL, Song JK, Newell DW. Cerebral aneurysms. N Engl J Med 2006;355:928-939.

3. Chang HS. Simulation of the natural history of cerebral aneurysms based on data from the International Study of Unruptured Intracranial Aneurysms.J Neurosurg 2006;104:188-194.

4. Suarez JI, Tarr RW, Selman WR. Aneurysmal subarachnoid hemorrhage. N Engl J Med 2006;354:387-396.

5. Clarke G, Mendelow AD, Mitchell P. Predicting the risk of rupture of intracranial aneurysms based on anatomical location. Acta Neurochir (Wien) 2005;147:259-263.

6. Horikoshi T, Akiyama I, Yamagata Z, Nukui H. Retrospective analysis of the prevalence of asymptomatic cerebral aneurysm in 4518 patients undergoing magnetic resonance angiography--when does cerebral aneurysm develop? Neurol Med Chir (Tokyo) 2002;42:105-113.

7. Resnick N, Yahav H, Shay-Salit A, et al. Fluid shear stress and the vascular endothelium:for better and for worse. Prog Biophys Mol Biol 2003;81:177-199.

8. Meng S, Geyer SH, Costa Lda F, Viana MP, Weninger WJ. Objective characterization of the course of the parasellar internal carotid artery using mathematical tools. Surg Radiol Anat 2008;30:519-526.

9. Vindlacheruvu RR, Mendelow AD, Mitchell P. Risk-benefit analysis of the treatment of unruptured intracranial aneurysms. J Neurol Neurosurg Psychiatry 2005;76:234-239.

10. Ecker RD, Hopkins LN. Natural history of unruptured intracranial aneurysms. Neurosurg Focus 2004;17:E4.

11. Guillemin F. [Critical analysis of the ISUIA study: the methodological point of view]. J Neuroradiol 2008;35:104-108.

12. Lee KC, Lee KS, Shin YS, Lee JW, Chung SK. Surgery for posterior communicating artery aneurysms. Surg Neurol 2003;59:107-113.

13. Uz A, Mine EK. A morphological study of the posterior communicating artery. Folia Morphol (Warsz) 2004;63:397-399.

14. Avci E, Bademci G, Ozturk A. Posterior communicating artery: from microsurgical, endoscopic and radiological perspective. Minim Invasive Neurosurg 2005;48:218-223.
15. Yoshimoto Y. A mathematical model of the natural history of intracranial aneurysms: quantification of the benefit of prophylactic treatment. J Neurosurg 2006;104:195-200.

16. Meng S, Costa LF, Geyer SH, et al. Three-dimensional description and mathematical characterization of the parasellar internal carotid artery in human infants. J Anat 2008;212:636-644.

17. Van Overbeeke JJ, Hillen B, Tulleken CA. A comparative study of the circle of Willis in fetal and adult life. The configuration of the posterior bifurcation of the posterior communicating artery. J Anat 1991;176:45-54.

18. Rinkel GJ, Djibuti M, Algra A, van Gijn J. Prevalence and risk of rupture of intracranial aneurysms: a systematic review. Stroke 1998;29:251-256.

19. Kailasnath P, Dickey P. ISUIA-II: the need to share more data. Surg Neurol 2004;62:95.

20. Hendrikse J, van Raamt AF, van der Graaf Y, Mali WP, van der Grond J. Distribution of cerebral blood flow in the circle of Willis. Radiology 2005;235:184-189.

21. Zhu H, Friedman MH. Relationship between the dynamic geometry and wall thickness of a human coronary artery. Arterioscler Thromb Vasc Biol 2003;23:2260-2265.

22. Tan HQ, Li MH, Zhu YQ, et al. Surgical construction of a novel simulated carotid siphon in dogs. J Neurosurg 2008;109:1173-1178.

23. Juvela S, Porras M, Heiskanen O. Natural history of unruptured intracranial aneurysms: a long-term follow-up study. J Neurosurg 1993;79:174-182.

24. Jamous MA, Nagahiro S, Kitazato KT, Satomi J, Satoh K. Role of estrogen deficiency in the formation and progression of cerebral aneurysms. Part I: experimental study of the effect of oophorectomy in rats. J Neurosurg 2005;103:1046-1051.

25. Jamous MA, Nagahiro S, Kitazato KT, Tamura T, Kuwayama K, Satoh K. Role of estrogen deficiency in the formation and progression of cerebral aneurysms. Part II: experimental study of the effects of hormone replacement therapy in rats. J Neurosurg 2005;103:1052-1057. 